\title{
Acceleration of Pine Island and Thwaites Glaciers, West Antarctica
}

\author{
Eric Rignot, ${ }^{1}$ David G. Vaughan, ${ }^{2}$ Marjorie Sahmeltz, ${ }^{1}$ Todd Dupont, ${ }^{3}$ Douglas MagAyeal ${ }^{4}$ \\ ${ }^{1}$ Jet Propulsion Laboratory, California Institute of Technology, 4800 Oak Grove Drive, Pasadena, CA 91109-8099, U.S.A. \\ ${ }^{2}$ British Antarctic Survey, Natural Environment Research Council, Madingley Road, Cambridge CB3 OET, England \\ ${ }^{3}$ Geosciences, The Pennsylvania State University, University Park, PA 16802-7501, U.S.A. \\ ${ }^{4}$ Department of Geophysical Sciences, University of Chicago, Chicago, IL 60637, U.S.A.
}

\begin{abstract}
Recent satellite investigations revealed that in the 1990s the grounding line of Pine Island and Thwaites Glaciers, West Antarctica, retreated several km, the ice surface on the interior of the basins lowered $10 \mathrm{~cm} \mathrm{a}^{-1}$, and Pine Island Glacier thinned $1.6 \mathrm{~m} \mathrm{a}^{-1}$. These observations, however, were not sufficient to determine the cause of the changes. Here, we present satellite radar interferometry data that show the thinning and retreat of Pine Island Glacier are caused by an acceleration of ice flow of about $18 \pm 2 \%$ in 8 years. Thwaites Glacier maintained a nearly constant flow regime at its center, but widened along the sides, and increased its $30 \pm 15 \%$ mass deficit by another $4 \%$ in 4 years. The combined mass loss from both glaciers, if correct, contributes an estimated $0.08 \pm 0.03 \mathrm{~mm} \mathrm{a}^{-1}$ global sea-level rise in 2000 .
\end{abstract}

\section{INTRODUGTION}

Of the three main glacier systems that drain the West Antarctic ice sheet, the one comprising Pine Island and Thwaites Glaciers is thought to be the most unstable (Hughes, 1981; Bentley, 1997). Loss of the ice contained in the ice-drainage basins and glaciers that disgorge into the Amundsen Sea (Fig. 1) could raise global sea level by $1.2 \mathrm{~m}$ (this estimate is obtained from the ice volume above sea level extracted from the BEDMAP thickness map (Lythe and others, 2001) over the drainage basins occupied by the glaciers) and promote increased discharge of the remainder of the West Antarctic ice sheet. Earlier assessments of input vs output of ice from these basins have not shown measurable imbalance (Bentley and Giovinetto, 1991), but these assessments contained major uncertainties (Vaughan and others, 2001).

More recently, satellite radar interferometry data showed that the grounding line of Pine Island Glacier retreated rapidly in the early 1990s (Rignot, 1998) and that the glacier mass balance might well be negative. A similar analysis conducted on Thwaites Glacier also indicated rapid groundingline retreat and thinning (Rignot, 2001). Satellite radar altimetry data subsequently confirmed the thinning of Pine Island Glacier, with a thinning rate approaching $1.6 \mathrm{~m} \mathrm{a}^{-1}$ near the grounding line (Shepherd and others, 2001). At larger scale, the drainage basins of Pine Island and Thwaites Glaciers thinned $10 \mathrm{~cm} \mathrm{a}^{-1}$ in the 1990s (Wingham and others, 1998). While these data indicate that important changes are taking place in this part of West Antarctica, they are not sufficient to determine the cause of the changes.

Here, we apply a satellite interferometry technique (Rignot and others, 1997) to synthetic aperture radar images acquired by the European Remote-sensing Satellites ERS-1 and -2. The resulting images allow us to map the flow of Pine
Island and Thwaites Glaciers with sufficient precision to measure substantial changes in flow velocity between 1992 and 2000.

\section{METHODS}

For the period 1996-2000, measurements of flow velocity are obtained in the same line-of-sight direction of the radar, $\overline{L_{\mathrm{OS}}}$,

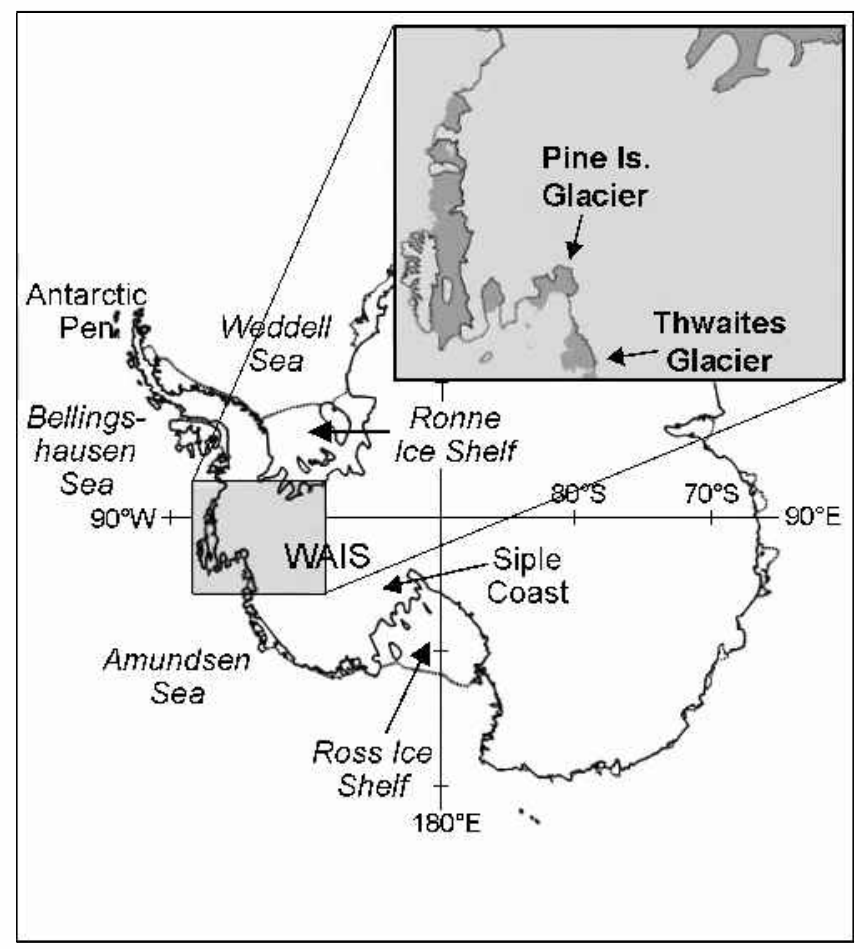

Fig. 1. Location map of Pine Island and Thwaites Glaciers, West Antarctica. 
Table 1. List of ERS-1/-2 dates and orbits used for Pine Island Glacier

\begin{tabular}{cllc}
\hline Track & \multicolumn{1}{c}{ ERS-1/-2 date } & ERS-1/-2 orbit & FES99 tide \\
\hline 35 & 15 Feb 1992/9 Feb 1992 & $3056 / 2970$ & $23.95 /-4.6$ \\
81 & 11 Nov 1995/12 Nov 1995 & $22614 / 2914$ & 27.4/32.6 \\
81 & 22 Jan 1996/23 Jan1996 & $23616 / 3943$ & $-41.6 /-33.8$ \\
81 & 24 Feb 1996/25 Feb 1996 & $24117 / 4444$ & $-10.2 /-22.6$ \\
81 & 20 Nov 1999/21 Nov 1999 & $43656 / 23983$ & $5.4 /-11.1$ \\
81 & 4 Mar 2000/5 Mar 2000 & $45159 / 25486$ & $-34.7 /-26.7$ \\
92 & 12 Nov 1995/13 Nov 1995 & 22625/2952 & $35.2 / 29.8$ \\
92 & 21 Jan 1996/22 Jan 1996 & $23627 / 3954$ & $81.2 / 72.2$ \\
\hline
\end{tabular}

Notes: Topographic mapping was performed combining 22625-2952 and 23627-3954 on track 92, and merging the results with the combination of 23616-3943 and 24117-4444 on track 81. The last column lists the tide predicted by the FES99 model at the time of passage of the satellite in $\mathrm{cm}$

using interferometric pairs spanning a 1 day time interval, acquired along descending track 81 of ERS (Table 1), and corrected for topography. Topography is calculated from interferometric pairs between which there is negligible change in glacier velocity (Table 1), and controlled by a digital elevation model of Antarctica (Bamber and Bindschadler, 1997). The line-of-sight velocities, $V_{96}^{\mathrm{Los}}$ and $V_{92}^{\mathrm{Los}}$, are

$$
\begin{aligned}
& V_{96}^{\mathrm{Los}}=\overline{V_{96}} \cdot \overline{L_{\mathrm{os}}}, \\
& V_{00}^{\mathrm{Los}}=\overline{V_{00}} \cdot \overline{L_{\mathrm{os}}} .
\end{aligned}
$$

where $\overline{V_{96}^{\mathrm{Los}}}$ and $\overline{V_{00}^{\mathrm{Los}}}$ are the vector velocities in 1996 and 2000, respectively. Comparison of the line-of-sight velocities yields a map of changes in velocity with a precision of $\pm 5 \mathrm{~m} \mathrm{a}^{-1}$ (Fig. 2)

From late 1995 to early 1996, sufficient tracks are

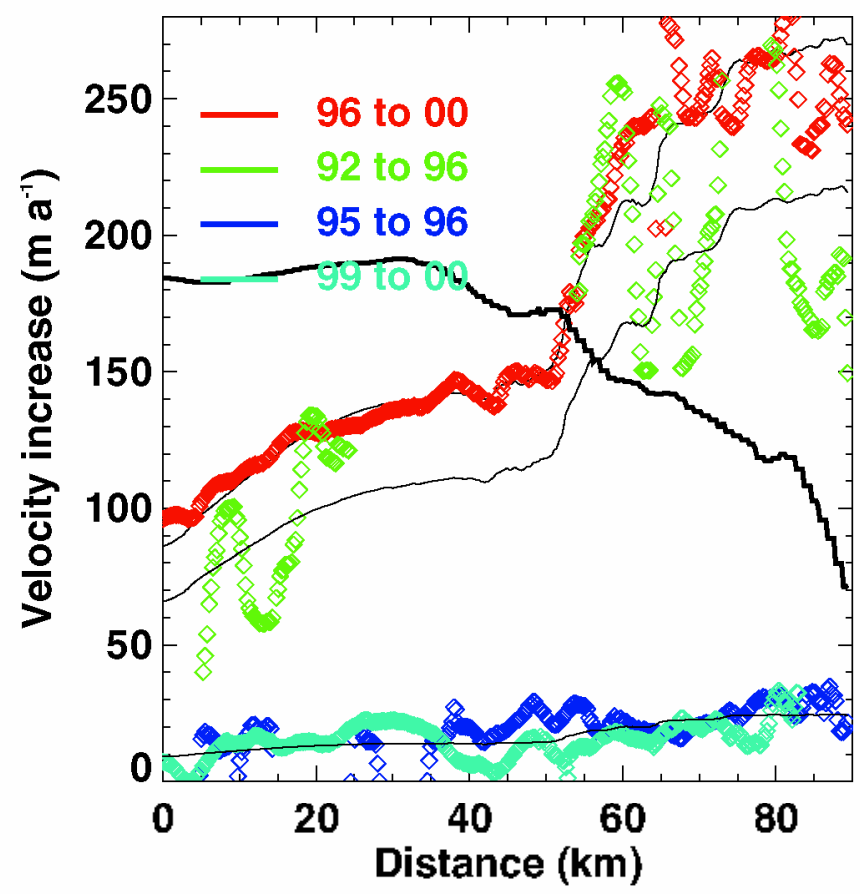

Fig. 3. Increase in velocity magnitude of Pine Island Glacier, from $A($ distance $=0)$ to $B($ distance $=90)$ in Figure $2 a$, from 15 February 1992 to 11 November 1995 in green, 11 November 1995 to 20 November 1999 in red, 11 November 1995 to 24 February 1996 in dark blue, and 20 November 1999 to 4 March 2000 in light blue. The thin black lines represent a percentage of the 1996 velocity, varying linearly from $6.5 \%$ in $A$ to $8 \%$ in $B$ for the time interval 1992-96, and from $8.5 \%$ in $A$ to $10 \%$ in B for the time interval 1996-2000, and fixed at $0.8 \%$ for the two 105 day time intervals (blue curves). The thick black line represents 1/10 of the ice thickness from BEDMAP from $A$ to $B$.
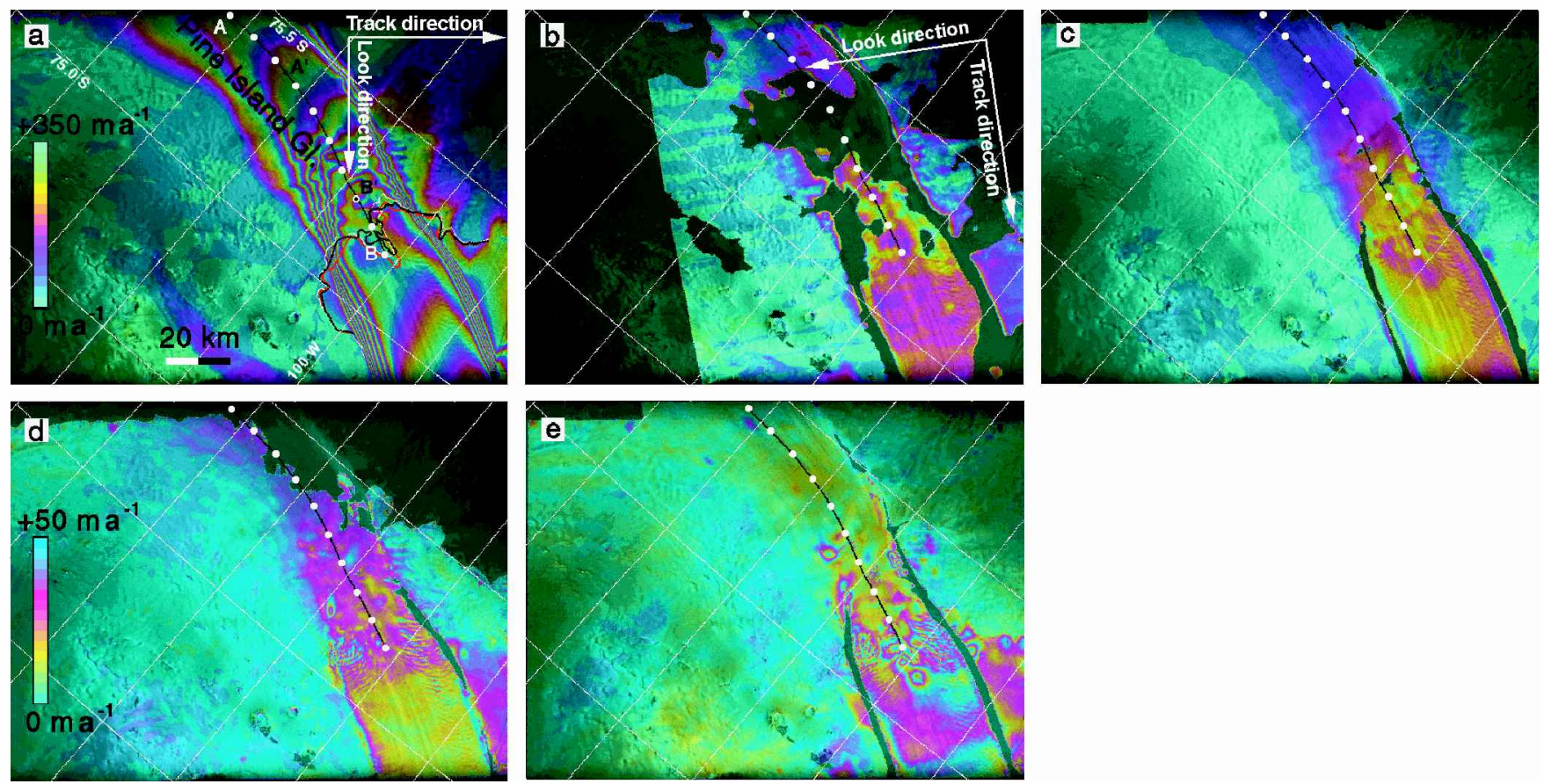

Fig. 2. (a) Line-of-sight velocity of Pine Island Glacier (positive down-glacier), 11 November 1995; grounding-line position in 1992 (red), 1996 (white) and 2000 (black), profile $A-B$ with white dots every $10 \mathrm{~km}$, and location of $A^{\prime}$ and $B^{\prime}$ discussed in the text (black dots). Each color cycle (from blue to red, yellow and blue again) in ( $a-c)$ represents a $350 \mathrm{~m} \mathrm{a}^{-1}$ increment in velocity, and $50 \mathrm{~m} \mathrm{a}^{-1}$ in $(d-e)$. (b) Increase in along-track velocity measured between 15 February 1992 and 11 November 1995 (1365 days). Increase in line-of-sight velocity measured between(c) 11 November 1995 and 20 November 1999 (1470 days), (d) 11 November 1995 and 24 February 1996 (105 days), and (e) 20 November 1999 and 4 March 2000 (105 days). 

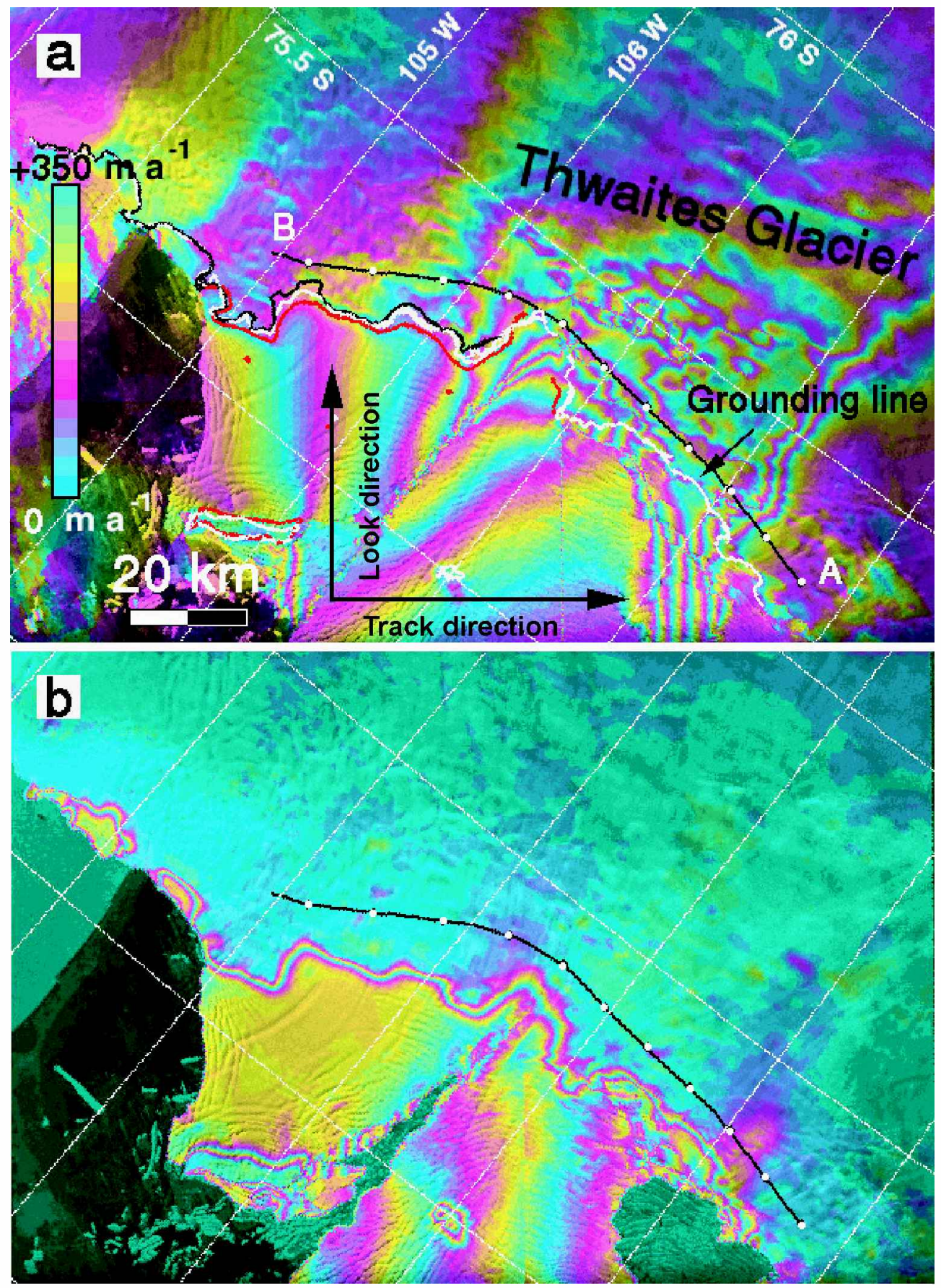

Fig. 4. (a) Line-of-sight velocity of Thwaites Glacier, 7 November 1995, track 24 (positive down-glacier); grounding-line position in 1992 (red), 1996 (white) and 2000 (black; incomplete data). Color code is the same as in Figure $2 a-c$. (b) Increase in line-of-sight velocity between 7 November 1995 and 29 February 2000 (1575 days). Profile A-B used in Figure 5 is black, with white dots spaced every $10 \mathrm{~km}$.

available along both the ascending and descending paths of ERS to allow a vector mapping of ice velocity, $\overline{V_{96}}$ (Table 1 ). The measurements of ice velocity were corrected for tide on the ice shelf using tidal predictions from the FES99 model (Lefevre and others, 2000) listed in Table 1. The vector map is used to convert the 1996-2000 changes in line-of-sight velocity into changes in velocity magnitude assuming no change in ice-flow direction between those years:

$$
\overline{V_{00}}=\left(1+\frac{V_{00}^{\mathrm{Los}}-V_{96}^{\mathrm{Los}}}{V_{96}^{\mathrm{Los}}}\right) \overline{V_{96}} .
$$

For the period 1992-96, the same method cannot be used since the 1992 interferometric pairs span 6 days instead of lday (Table 1), causing significant aliasing of the inter- ferometric phase. In addition, the 1992 tracks do not exactly coincide with the 1996 tracks. Instead, we measure the 1992 flow velocity, $V_{92}^{\mathrm{ST}}$, using a speckle-tracking (ST) technique (Michel and Rignot, 1999) in the along-track direction, $\bar{t}$, of an ascending pass of ERS:

$$
V_{92}^{\mathrm{ST}}=\overline{V_{92}} \cdot \bar{t},
$$

where $\bar{V}_{92}$ is the 1992 vector velocity. The precision of speckle tracking is $1 / 30$ of a pixel, which is $4 \mathrm{~m}$ long in the along-track direction. Over a period of 6 days, this means a precision in $V_{92}^{\mathrm{ST}}$ of $10 \mathrm{~m} \mathrm{a}^{-1}$. However, small undulations in pixel offset, probably caused by ionospheric disturbances (1992 was near solar maximum), limit the precision in the present case to $\pm 30 \mathrm{~m} \mathrm{a}^{-1}$. Speckle tracking is also applic- 


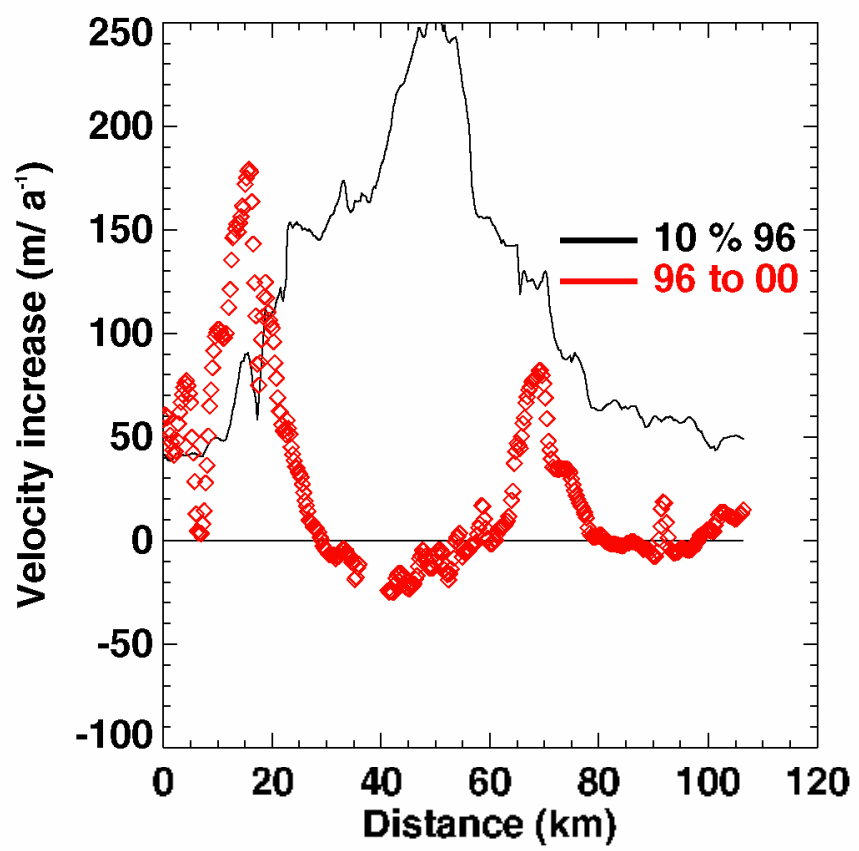

Fig. 5. Increase in velocity magnitude of Thwaites Glacier, from $A$ (distance $=0)$ to $B($ distance $=107)$, November 1995-February 2000, in red. The thin black line represents 10\% of the 1996 velocity for reference.

able in the cross-track (line-of-sight) direction, but the pixel size in that direction is too large $(20 \mathrm{~m})$ to measure changes in ice velocity with sufficient precision.

The along-track velocity, $V_{92}^{\mathrm{ST}}$ is compared to its 1996 equivalent by projecting the 1996 vector velocity along the same direction,

$$
V_{96}^{\mathrm{ST}}=\overline{V_{96}} \cdot \bar{t} .
$$

Assuming no change in flow direction between 1992 and 1996, the 1992 flow vector is deduced from the 1996 flow vector using

$$
\overline{V_{92}}=\left(1+\frac{V_{92}^{\mathrm{ST}}-V_{96}^{\mathrm{ST}}}{V_{96}^{\mathrm{ST}}}\right) \overline{V_{96}} .
$$

The 1992 and 2000 velocity changes (Fig. 2b and c) are compared to the 1996 reference velocity (Fig. 2a) in Figure 3 along the approximate center line of the glacier. Note that the 1992 along-track direction, $\bar{t}$, and the 1996 line-of-sight direction, $\overline{L_{\mathrm{OS}}}$, differ only by $11^{\circ}$.

\section{RESULTS}

Figure 3 shows that the flow acceleration of Pine Island Glacier coincides with the fast-flowing part of the glacier. It is largest at the grounding line, and affects both $>100 \mathrm{~km}$ of grounded ice and the floating ice shelf. The velocity increase is $100 \mathrm{~m} \mathrm{a}^{-1}$ at the inland edge of the scene, or $8.5 \%$ of the 1996 velocity. It becomes $250 \mathrm{~m} \mathrm{a}^{-1}$ at the grounding line, or $10 \%$ of the 1996 velocity. The flow acceleration therefore decreases inland, decreases on the floating ice shelf (visible in Fig. 2, but not in Fig. 3) and is largest near the grounding zone.

The 1992-96 flow acceleration varies from $6.5 \%$ of the 1996 velocity near $\mathrm{km} 0$ to $8 \%$ near the grounding line. If the 1992 velocity is used as a reference, the percentage flow change becomes $6 \%$ and $7.5 \%$, respectively. Within the uncertainty of the $1992-96$ measurement $( \pm 1 \%)$, the flow
Table 2. List of ERS-1/-2 dates and orbits used for Thwaites Glacier

\begin{tabular}{clcc}
\hline Track & \multicolumn{1}{c}{ ERS-1/-2 date } & ERS-1/-2 orbit & FES99 tide \\
& & & \\
\hline 10 & 8 Mar 1992/2 Mar 1992 & $3375 / 3289$ & $-9.0 /-25.1$ \\
24 & 12 Nov 1995/13 Nov 1995 & $22557 / 2884$ & $29.3 / 30.8$ \\
24 & 16 Jan 1996/17 Jan 1996 & $23559 / 3886$ & $-35.4 /-39.1$ \\
24 & 29 Feb 2000/1 Mar 2000 & $45102 / 25429$ & $-48.6 /-47.6$ \\
24 & 16 Nov 1999/17 Nov 1999 & $43599 / 23926$ & $35.5 / 32.5$ \\
350 & 8 Feb 1996/9 Feb 1996 & $23885 / 4212$ & $13.7 / 3.9$ \\
350 & 14 Mar 1996/15 Mar 1996 & $24386 / 4713$ & $-24.8 /-15.7$ \\
& & & \\
\hline
\end{tabular}

Notes: Topographic mapping was performed combining 22557-2884 and 23559-3886 on track 24, and merging the results with the combination of 23885-4212 and 24386-4713 on track 350. The last column lists the tide predicted by the FES99 model at the time of passage of the satellite in $\mathrm{cm}$.

acceleration is therefore larger in 1996-2000 than in 199296, and hence increases with time.

Image pairs acquired 105 days apart in late 1996 and 2000 (Fig. 2d and e) also show a flow acceleration, which suggests that the flow change is nearly continuous through time. The result also shows that flow changes over just 2 months are large enough to be detected with interferometric synthetic aperture radar (InSAR).

No flow acceleration is detected across the central part of Thwaites Glacier(Fig. 4) between 1996 and 2000. In fact, the central part of the glacier experienced a slight reduction in ice velocity. However, two sectors about $10 \mathrm{~km}$ wide by $30 \mathrm{~km}$ long, near the grounding line, along the shear margins of the glacier, accelerated $4-20 \%$ (Fig. 5). This pattern of flow change indicates that the glacier shear margins migrated outward, by several $\mathrm{km}$. The widening of the fas-flow portion of the glacier increased the mean velocity, and hence ice discharge, by about $4 \%$, despite the relative slow-down of the central part of the glacier.

\section{DISGUSSION}

\subsection{Mass balance}

A consequence of the flow acceleration of Pine Island Glacier is that its basin is now certainly losing mass. Using ice thickness from BEDMAP (Lythe and Vaughan, 2001) and the 1996 vector velocity map, the grounding-line flux is $75.1 \pm 4 \mathrm{~km}^{3}$ ice $\mathrm{a}^{-1}$ in 1996 , with a precision limited by $\mathrm{a} \pm 50 \mathrm{~m}$ uncertainty in thickness. This result compares well with the $76.1 \pm 2 \mathrm{~km}^{3}$ ice $\mathrm{a}^{-1}$ grounding-line flux estimated using an ice thickness deduced from hydrostatic equilibrium (Rignot, 1998). Using Equation (2), the flux is estimated at $82.6 \pm 4 \mathrm{~km}^{3}$ ice $\mathrm{a}^{-1}$ in 2000 , which is $10 \%$ higher. The $159120 \mathrm{~km}^{2}$ basin of Pine Island Glacier accumulates $68.0 \mathrm{~km}^{3}$ ice $\mathrm{a}^{-1}$ according to Vaughan and others' (1999) accumulation map, and $71.6 \mathrm{~km}^{3}$ ice $\mathrm{a}^{-1}$ according to Giovinetto and Zwally's (2000). The averagevalue is $69.8 \mathrm{~km}^{3}$ ice $\mathrm{a}^{-1}$, with a $3 \mathrm{~km}^{3}$ ice $\mathrm{a}^{-1}$ uncertainty. The glacier mass balance is thus $-12.8 \pm 5 \mathrm{~km}^{3}$ ice $\mathrm{a}^{-1}$ in 2000, compared to $-5.3 \pm 5 \mathrm{~km}^{3}$ ice $\mathrm{a}^{-1}$ in 1996. Similarly, using Equation (5), the glacier mass balance was only $-0.7 \pm 5 \mathrm{~km}^{3}$ ice $\mathrm{a}^{-1}$ in 1992 .

The grounding-line discharge of Thwaites Glacier was estimated at $77 \pm 8 \mathrm{~km}^{3}$ ice $\mathrm{a}^{-1}$ in 1996, with an accumulation of $60.0 \pm 3 \mathrm{~km}^{3}$ ice $\mathrm{a}^{-1}$ (average of the two accumulation maps) over a basin area of $166500 \mathrm{~km}^{2}$ (Rignot, 2001). In 
2000 , the grounding-line discharge is $80.1 \pm 8 \mathrm{~km}^{3}$ ice $\mathrm{a}^{-1}$, or $4 \%$ higher, and the mass balance is thus $-20.1 \pm 9 \mathrm{~km}^{3}$ ice $\mathrm{a}^{-1}$.

The combined mass balance of the basins of Pine Island and Thwaites Glaciers is $-33 \pm 10 \mathrm{~km}^{3}$ ice $\mathrm{a}^{-1}$, or $30 \pm 9$ $\mathrm{Gt} \mathrm{a}^{-1}$ using an ice density of $917 \mathrm{~kg} \mathrm{~m}^{-3}$. If correct, this contributes a $0.08 \pm 0.02 \mathrm{~mm} \mathrm{a}^{-1}$ global sea-level rise, using 360 $\mathrm{Gt} \mathrm{a}^{-1}$ as the equivalent to a $1 \mathrm{~mm}$ sea-level rise (Jacobs and others, 1992).

Using the BEDMAP thickness models, we calculate that Pine Island and Thwaites Glaciers contain 396330 and $306910 \mathrm{~km}^{3}$ of ice, respectively, of which 250590 and $210460 \mathrm{~km}^{3}$, respectively, are above sea level. Complete removal of ice from the basins would raise sea level by 0.7 and $0.55 \mathrm{~m}$, respectively, for a combined total of $1.25 \mathrm{~m}$. Hence, a sustained mass loss from this sector of West Antarctica would have a significant impact on sea level.

\subsection{Ice thinning}

The flow acceleration of Pine Island Glacier could either thin or thicken the ice, depending on the rate of flow change. Thicker ice advected from upstream causes thickening downstream, while enhanced longitudinal stretching of the ice creates a negative vertical strain which causes ice to thin. This is illustrated through the conservation-of-mass relationship applied to a vertical column of ice:

$$
\frac{\partial H}{\partial t}=\dot{a}+\dot{b}-\bar{V} \cdot \nabla H+H \dot{\epsilon}_{z},
$$

where $\partial H / \partial t$ is the glacier thickening rate, $\dot{a}$ is the surface accumulation, $\dot{b}$ is basal accumulation, $\bar{V}$ is the velocity vector, $\nabla$ is the horizontal gradient operator, and $\dot{\epsilon}_{z}$ is the vertically averaged vertical strain rate. The third term on the righthand side of the equation corresponds to thickening from advection, while the fourth term corresponds to thinning from vertical strain. If the glacier velocity increases by $\delta \bar{V}$, the thickening rate will change by

$$
\delta(\partial H / \partial t)=-\delta \bar{V} \cdot \nabla H+H \delta \dot{\epsilon}_{z},
$$

where $\delta \dot{\epsilon}_{z}$ is the change in strain rate. The change in ice thickness, $\delta H=1-2 \mathrm{ma}^{-1}$ according to Shepherd and others (2001), is here neglected.

We apply Equation (7) at two locations along profile A-B: (1) at $\mathrm{km} 25$ (point $\mathrm{A}^{\prime}$ in Fig. 2) between $\mathrm{km} 0$ and 50; and (2) at $\mathrm{km} 60$ (point $\mathrm{B}^{\prime}$ in Fig. 2) between $\mathrm{km} 50$ and 70. At $\mathrm{A}^{\prime}$ in 2000, we use: $H=1850 \mathrm{~m}, \nabla H=(1700-1850) /\left(5 \times 10^{4}\right), \delta \bar{V}=$ $130 \mathrm{~m} \mathrm{a}^{-1}$, and $\delta \dot{\epsilon}_{z}=-(150-100) /\left(5 \times 10^{4}\right) \mathrm{a}^{-1}$. The calculated change in ice thickness is $-0.4 \pm 0.2 \mathrm{~m} \mathrm{a}^{-1}$ for $1996-2000$. The $0.2 \mathrm{~m} \mathrm{a}^{-1}$ uncertainty is deduced from a $\pm 10 \mathrm{~m} \mathrm{a}^{-1}$ uncertainty in velocity and $\mathrm{a} \pm 50 \mathrm{~m}$ uncertainty in thickness. At $\mathrm{B}^{\prime}$, we have $H=1450 \mathrm{~m}, \nabla H=(1350-1700) /\left(2 \times 10^{4}\right), \delta \bar{V}=200$ $\mathrm{m} \mathrm{a}^{-1}$, and $\delta \dot{\epsilon}_{z}=-(250-150) /\left(2 \times 10^{4}\right) \mathrm{a}^{-1}$. The calculated rate of thickness change is $-0.94 \pm 0.4 \mathrm{~m}$ ice $\mathrm{a}^{-1}$ for 1996-2000.

At $\mathrm{A}^{\prime}$ in $1996, \delta \bar{V}=110 \mathrm{ma}^{-1}$, and $\delta \dot{\epsilon}_{z}=-(115-65) /$ $\left(5 \times 10^{4}\right) \mathrm{a}^{-1}$ yield a thickness change of $-0.4 \pm 0.2 \mathrm{~m} \mathrm{a}^{-1}$ for 1992-96. At $\mathrm{B}^{\prime}, \delta \bar{V}=115 \mathrm{ma}^{-1}$ and $\delta \dot{\epsilon}_{z}=-(210-115) /$ $\left(2 \times 10^{4}\right) \mathrm{a}^{-1}$ yield a change in thickness of $-0.95 \pm 0.4 \mathrm{~m}$ ice $\mathrm{a}^{-1}$ for 1992-96.

Hence, despite slight changes in flow acceleration between the two time intervals, the inferred rates of thinning are consistent from 1992 to 2000 : $0.4 \mathrm{~m}^{-1} \mathrm{a}^{-1}$ about $65 \mathrm{~km}$ upstream of the grounding line, and $0.95 \mathrm{~m}$ ice $\mathrm{a}^{-1}$ about $15 \mathrm{~km}$ upstream of the grounding line.

These results compare well with Shepherd and others' (2001), but are probably lower in the case of $\mathrm{B}^{\prime}$. They report a mean thinning of $0.75 \pm 0.07 \mathrm{~m}$ ice $\mathrm{a}^{-1}$ in the lower $150 \mathrm{~km}$ of the glacier, and $1.6 \pm 0.2 \mathrm{~m} \mathrm{a}^{-1}$ about $13 \mathrm{~km}$ upstream of the grounding line. The thinning rate calculated using Equation (7), however, is in addition to that given by Equation (6), which is not known. The larger-magnitude thinning reported from satellite radar altimetry therefore suggests that the result of Equation (6) is negative, which means that the mass budget of the glacier would remain negative in the lower reaches even if there had been no acceleration in 1992-2000.

Thwaites Glacier, in contrast, shows no acceleration of its main trunk in 1992-2000. The estimate of the mass budget of its basin is, however, strongly negative, which means that the result of Equation (6) is negative. The migration of its shear margins in 1996-2000 suggests that the glacier has not reached stable flow conditions and that ice discharge may increase further in the future, augmenting the glacier mass deficit.

Thwaites Glacier must have accelerated in the past compared to equilibrium conditions. The flow increase, of the order of $30 \%$, must have taken place well before 1992 . The flow change of Thwaites Glacier is therefore likely of much older origin than that of Pine Island Glacier.

\subsection{Nature of flow changes}

The flow acceleration of Pine Island Glacier is unlike a conventional glacier surge, in which a bulge or surge front moves down-glacier as a kinematic wave at many times the ice velocity. A surge is usually expressed by a simultaneous acceleration and thickening of the glacier. Here, the flow change is accompanied by thinning (Rignot, 1998; Shepherd and others, 2001) over an extended period. Similarly, there is no evidence for a kinematic wave traveling up-glacier (Fig. 3), which would be expected if an abrupt change in ice-shelf condition were the cause of the acceleration.

Pine Island Glacier flows too rapidly to be frozen to its bed (Vaughan and others, 2001). It moves predominantly either by sliding over a non-deforming bed, or by resting on highly deformable basal sediments, or by a mix of the two mechanisms. In either case, the presence of basal water at a pressure close to the overburden pressure is required. An increase in basal water pressure would reduce the basal shear stress and enhance ice flow. The meltwater present beneath the glacier is produced in comparable amounts by both geothermal and frictional heating. An average geothermal flux of $54 \mathrm{~mW} \mathrm{~m}{ }^{-2}$ over the basin of Pine Island Glacier melts $0.8 \mathrm{Gta}^{-1}$, if we assume that only half of the available heat melts the ice. Given a basal shear stress of $115 \mathrm{kPa}$, a sliding velocity of $1 \mathrm{kma}^{-1}$, and a sliding area of $30 \times 100 \mathrm{~km}$ (Vaughan and others, 2001), frictional heating melts about $0.7 \mathrm{Gta}^{-1}$. Frictional heating will not change unless the glacier speeds up considerably. Geothermal heating could be enhanced by several orders of magnitude near active volcanoes (Clarke and others, 1989), some of which are known to be present in the area (LeMasurier and Thompson, 1990). Yet we have no evidence for recent volcanic activity in the area; and it is also unclear how subglacial volcanic activity could sustain a nearly constant rate of flow acceleration for well over a decade.

No remarkable change in ice-front position has been detected on Pine Island Glacier (Jenkins and others, 1997). This situation may now be changing, however, as there is new evidence of cracking and fissuring of the ice shelf in 
Pine Island Bay (Rignot, in press). Assuming that the ice shelf exerts a buttressing effect on the inland ice, its progressive disappearance could in principle yield a flow acceleration similar to that observed with InSAR. This possibility is being investigated at present using numerical modeling, and the results will be reported in the future.

Although recent changes in ice velocity were reported in another main ice-stream/glacier system draining the West Antarctic ice sheet, the Siple Coast (Whillans and others, 2001) flow either slowed down or reverted to what it was beforehand, which was viewed by Bentley (1997) as being consistent with long-term equilibrium. The third major drainage route from West Antarctica, the Ronne Ice Shelf, shows no pronounced evidence of large imbalance or flow acceleration on the ice shelf (Doake and others, 2001). Observed flow changes on Pine Island and Thwaites Glaciers therefore constitute the most compelling evidence for substantial contemporary ice-sheet retreat in West Antarctica. The observed changes are large, well documented, faster than anticipated and affect large areas. The consequences for the basins drained by these glaciers are significant in terms of their contribution to sea-level change.

\section{GONGLUSIONS}

Using satellite radar interferometry data, the grounding line of Pine Island Glacier was shown to retreat rapidly. Satellite altimetry data showed that thinning extended inland, over a large area, and was coincident with the area of fast flow of the ice. These observations suggested a dynamic effect was responsible for the observed thinning and grounding-line retreat. The data presented here fully demonstrate the dynamic nature of ice thinning in this region. The results, in turn, illustrate the high complementarity of satellite altimetry and satellite interferometry for documenting glacier changes.

\section{ACKNOWLEDGEMENTS}

This work was performed at the Jet Propulsion Laboratory, California Institute of Technology, under a contract with the National Aeronautics and Space Administration, Polar Program. The European Space Agency and the Canadian Space Agency are acknowledged for collecting and distributing the radar data employed in this study. We also thank T. Scambos, B. Lucchitta and S. Price for their reviews.

\section{REFERENGES}

Bamber, J. L. and R. A. Bindschadler. 1997. An improved elevation dataset for climate and ice-sheet modelling: validation with satellite imagery. Ann. Glaciol., 25, 439-444.

Bentley, C. R. 1997. Rapid sea-level rise soon from West Antarctic ice sheet collapse? Science, 275(5303), 1077-1078.

Bentley, C. R. and M. B. Giovinetto. 1991. Mass balance of Antarctica and sea level change. InWeller, G., C. L. Wilson and B. A. B. Severin, eds. International Conference on the Role of the Polar Regions in Global Change: proceedings of a conference held June 11-15,1990 at the University of Alaska Fairbanks. Vol. II. Fairbanks, AK, University of Alaska. Geophysical Institute/Center for Global Change and Arctic System Research, 481-488.

Clarke, G. K. C., G. M. Cross and C. S. Benson. 1989. Radar imaging of glaciovolcanic stratigraphy, Mount Wrangell caldera, Alaska: interpretation model and results. F. Geophys. Res., 94(B6), 7237-7249.

Doake, C. S. M. and 7 others. 2001. Rutford Ice Stream, Antarctica. In Alley, R. B. and R. A. Bindschadler, eds. The West Antarctic ice sheet: behavior and environment. Washington, DC, American Geophysical Union, 221-235. (Antarctic Research Series 77.)

Giovinetto, M. B. and H. J. Zwally. 2000. Spatial distribution of net surface accumulation on the Antarctic ice sheet. Ann. Glaciol., 31, 171-178.

Hughes, T.J. 1981. Correspondence. The weak underbelly of the West Antarctic ice sheet. F. Glaciol., 27(97), 518-525.

Jacobs, S. S., H. H. Hellmer, C. S. M. Doake, A. Jenkins and R. M. Frolich. 1992. Melting of ice shelves and the mass balance of Antarctica. F. Glaciol., 38(130), 375-387.

Jenkins, A., D. G. Vaughan, S. S. Jacobs, H. H. Hellmer and J. R. Keys. 1997. Glaciological and oceanographic evidence of high melt rates beneath Pine Island Glacier, West Antarctica. 7. Glaciol., 43(143), 114-121.

Lefevre, F., F. H. Lyard and C. le Provost. 2000. FES98: a new global tide finite element solution independent of altimetry. Geophys. Res. Lett., 27(17), 2717-2720.

LeMasurier, W.E. and J.W. Thomson. 1990. Volcanoes of the Antarctic plate and southern oceans. Washington, DC, American Geophysical Union. (Antarctic Research Series 48.)

Lythe, M. B., D. G. Vaughan and BEDMAP Consortium. 2001. BEDMAP: a new ice thickness and subglacial topographic model of Antarctica. 7 . Geophys. Res., 106(B6), 11,335-11,351.

Michel, R. and E. Rignot. 1999. Flow of Glaciar Moreno, Argentina, from repeat-pass Shuttle Imaging Radar images: comparison of the phase correlation method with radar interferometry. F. Glaciol., 45(149), 93-100.

Rignot, E. J. 1998. Fast recession of a West Antarctic glacier. Science, $281(5376), 549-551$.

Rignot, E. 2001. Evidence for rapid retreat and mass loss of Thwaites Glacier, West Antarctica. 7. Glaciol., 47(157), 213-222.

Rignot, E. In press. Ice-shelf changes in Pine Island Bay, Antarctica, 19472000. 7. Glaciol.

Rignot, E. J., S. P. Gogineni, W. B. Krabill and S. Ekholm. 1997. North and north-east Greenland ice discharge from satellite radar interferometry. Science, 276(5314), 934-937.

Shepherd, A., D. J. Wingham, J. A. D. Mansley and H. F. J. Corr. 2001. Inland thinning of Pine Island Glacier, West Antarctica. Science, 291 (5505), 862-864.

Vaughan, D. G., J. L. Bamber, M. B. Giovinetto, J. Russell and A. P. R. Cooper. 1999. Reassessment of net surface mass balance in Antarctica. 7. Climate, 12(4), 933-946.

Vaughan, D. G. and 9 others. 2001. A review of Pine Island Glacier basin, West Antarctica: hypotheses of instability vs. observations of change. In Alley, R. B. and R. A. Bindschadler, eds. The West Antarctic ice sheet: behavior and environment. Washington, DC, American Geophysical Union, 237-256. (Antarctic Research Series 77.)

Whillans, I. M., C. R. Bentley and C. J. van der Veen. 2001. Ice Streams B and C. In Alley, R. B. and R. A. Bindschadler, eds. The West Antarctic ice sheet: behavior and environment. Washington, DC, American Geophysical Union, 257-281. (Antarctic Research Series 77.)

Wingham, D. J., A. L. Ridout, R. Scharroo, R. J. Arthern and C. K. Shum. 1998. Antarctic elevation change 1992 to 1996. Science, 282(5388), 456-458. 